\title{
As bibliotecas infantis e os bibliotecários: afinando competências
}

\author{
The childrens's libraries and librarians: tuning skills
}

\begin{abstract}
Melissa Pedroso Fusatto
Bacharel em Biblioteconomia, Ciências da Informação e da Documentação pela Faculdade de Filosofia, Ciências e Letras de Ribeirão Preto - FFCLRP/USP.

E-mail: mellfuzatto@rocketmail.com

Márcia Regina Silva

Doutora em Educação pela Universidade Federal de São Carlos - UFSCar. Docente do curso de Ciências da Informação e da Documentação e Biblioteconomia da Faculdade de Filosofia, Ciências e Letras de Ribeirão Preto - FFCLRP/USP.

E-mail: marciaregina@usp.br
\end{abstract}

\section{Resumo}

Este trabalho buscou identificar o perfil do bibliotecário que atua em bibliotecas infantis no que se refere à formação do leitor. Para alcançar este objetivo foram levantadas as atividades direcionadas ao público infantil, disponíveis em sites de 19 bibliotecas brasileiras e norte-americanas. Além disso, foram realizadas entrevistas com cinco profissionais que atuam e/ou atuaram no desenvolvimento de ações voltadas ao público infantil. O resultado do levantamento de dados e das entrevistas foi comparado à literatura científica da área, tornando possível a construção de um quadro contendo qualidades consideradas imprescindíveis para atuação do bibliotecário no processo de formação do leitor. A análise das atividades executadas em bibliotecas brasileiras e norte-americanas permitiu também uma percepção sobre o foco das ações desenvolvidas nos dois países: enquanto nos Estados Unidos da América as bibliotecas desenvolvem atividades voltadas à formação educacional das crianças, ou seja, ao apoio à escola. No Brasil o foco dessas ações é a formação cultural e as atividades que ainda buscam consolidar o papel da Biblioteca na sociedade.

Palavras-chave: Biblioteca infantil. Formação do Leitor. Bibliotecário. Competências.

\begin{abstract}
This study aimed to identify the professional profile required for the librarian who works in children's libraries in relation the training of readers. To achieve this objective were raised child targeted activities available in 19 public Brazilian and U.S. libraries websites. Furthermore, interviews with five professionals who work and/or acted with care to children were held. The result of data collection and interviews were compared to the scientific literature in the field, making it possible to build a board containing qualities considered essential for performance of the librarian in the training process of the reader. The analysis of the executed activities in Brazilian and American libraries permitted also a notion about the focus of the actions developed in both countries: while in U.S. libraries develop activities targeting the children's education, that is, supporting the school activities. In Brazil the focus of these actions is the cultural formation and the activities that still look to consolidate the library function in the society.
\end{abstract}

Keywords: Children's Libraries. Training of readers. Librarian. Skills. 


\section{Introdução}

Os currículos dos cursos de Biblioteconomia no Brasil possuem pouca ênfase em disciplinas com foco no contexto das bibliotecas infantis. Os profissionais que atuam nestes ambientes informacionais adaptam os conhecimentos adquiridos durante sua formação a uma realidade muitas vezes desconhecida. Apesar disso, observa-se que há um grande esforço dos bibliotecários em dinamizar sua atuação neste setor.

A biblioteca infantil é um ambiente que possui características próprias e, para se tornarem verdadeiros locais de aprendizagem, precisam oferecer recursos bibliográficos condizentes com o perfil de seus usuários e, principalmente, deve contar com um profissional - o bibliotecário - que seja dinâmico e criativo, disposto a propor ações que interfiram efetivamente na formação de leitores críticos. Além disso, as bibliotecas infantis devem ter caráter lúdico: brincadeiras e contações de histórias devem fazer parte das atividades educativas oferecidas neste ambiente. Bueno e Steindel (2006) afirmam que o lúdico está no ato de apropriação da literatura como forma natural de descobrimento e compreensão de mundo. Esse tipo de atividade atrai a atenção das crianças e pode se constituir em um mecanismo de potencialização da aprendizagem.

Segundo Melo e Neves (2005, p. web) “os avanços tecnológicos e as contínuas mudanças sociais reivindicam processos educativos mais criativos e mais dinâmicos que se realizam, à medida que possibilitam à criança uma educação permanente". Neste sentido, o bibliotecário de bibliotecas infantis tem um papel importante no processo de ensino e aprendizagem ao estimular o gosto pela leitura e desenvolver aptidões e senso de responsabilidade em seus usuários. E é justamente por seu caráter formativo, que a biblioteca infantil deve ser um espaço planejado e tornar o primeiro contato da criança com os recursos informacionais mais agradável e natural, de forma que ela passe a ser um usuário constante e atuante deste espaço.

O perfil do profissional que atua em bibliotecas infantis vai além dos conhecimentos técnicos de organização de acervos. Este profissional deve sentir prazer em atender este público diferenciado, ser criativo, pró-ativo, paciente, conhecer literatura infantil, saber contar histórias, conhecer recursos e mobílias especiais. Dessa forma, esse profissional deve ter habilidades, competências e atitudes que estejam em consonância com as necessidades de um público diferenciado. 
Em 2010 foi promulgada a Lei $\mathrm{n}^{\circ} 12.244$ que trata da universalização das bibliotecas escolares no Brasil. Esta Lei prevê que qualquer escola, seja pública ou privada, deve possuir obrigatoriamente uma biblioteca em condições suficientes para atender o número de alunos matriculados. Esta Lei é importante no sentido de que, no Brasil, a maioria das bibliotecas infantis se caracteriza também como bibliotecas escolares, isso porque estão inseridas nas estruturas das escolas. Embora saibamos que ainda pairam muitas dúvidas sobre a execução desta Lei, entendemos a necessidade de formação de profissionais para o atendimento desta demanda.

Espera-se que com mais bibliotecários nas escolas, as crianças despertem seus sentidos para apreciar a leitura, porém, para que isso aconteça o profissional atuante nesse ambiente deve empenhar esforços para atrair as crianças para a biblioteca e desenvolver atividades para conquistá-las, fidelizando os pequenos usuários.

O objetivo deste artigo é identificar o perfil do bibliotecário que atua em bibliotecas infantis no que se refere a formação do leitor. Para tal, além de entrevistas, foram levantadas as principais ações desenvolvidas em bibliotecas infantis nacionais e internacionais. Este levantamento permitiu observar se as competências exigidas desses profissionais condizem com as ações executadas em ambientes infantis e informacionais.

\section{O papel das bibliotecas infantis na formação de leitores}

As bibliotecas infantis são extremamente importantes no processo de formação do leitor. Muitas vezes, esse é o primeiro ambiente onde as crianças dão seus primeiros passos para tornarem-se verdadeiros leitores, podem ter acesso a variedades literárias e têm atenção de um mediador de leitura que o direciona na escolha de obras que estão de acordo com sua faixa etária. A figura do bibliotecário pode influenciar o gosto de leitura, uma vez que ele deve propor ações lúdicas e estratégicas que possam tornar a experiência de leitura na biblioteca cristalizadora.

Porém, segundo Silva (2005) as bibliotecas tornaram-se, aos poucos, receptáculos passivos, abstraindo o caráter político e educativo do trabalho biblioteconômico, dando maior ênfase às funções técnicas de preservar e organizar documentos. Dessa forma, as funções sociais tanto da biblioteca quanto do profissional da informação foram ofuscadas. 
As bibliotecas infantis geralmente estão localizadas no ambiente interno das escolas e podem ocupar um espaço próprio, um canto da biblioteca escolar destinado ao público infantil e, ainda, estender-se às salas de aula por meio dos espaços de leitura. Independentemente de sua localização, a biblioteca (e não apenas as infantis) deve preocupar-se em prover não o simples acesso à informação de qualidade, mas promover práticas de leitura mostrando aos iniciantes que há muito a se explorar nesse universo.

Para que essa tarefa seja realizada, é imprescindível que toda a equipe escolar esteja integrada: professores, bibliotecários, equipe administrativa e outros. Mas, conforme Mollo e Nóbrega (2011), além da integração entre os profissionais que atuam na instituição, é necessário que a biblioteca esteja preparada para funcionar bem, dispondo de um espaço agradável, acervo impresso e digital que atenda às demandas tanto da pesquisa escolar quanto da leitura literária.

A Lei 12.244 visa mudar uma realidade que está longe de ser ideal. Muitas escolas, principalmente as públicas, não oferecem aos alunos um acervo de qualidade deixando à disposição apenas os livros indicados para provas. O profissional que trabalha neste setor geralmente não é um bibliotecário, consequentemente, não consegue fazer da biblioteca um centro de informação de qualidade, assim como afirmam Mollo e Nóbrega (2011, p. 9):

Infelizmente, ainda é muito recorrente que a biblioteca escolar, quando ela existe,
seja gerenciada por um funcionário não especializado, às vezes, afastado do contato
direto com os alunos por motivo de saúde. Ser apaixonado pela leitura e manter
acesa a curiosidade são requisitos essenciais para o exercício dessa tarefa que
promove o encontro amoroso entre o texto e o leitor. (Grifo nosso)

A presença de um profissional preparado é fator indispensável para tornar a biblioteca atraente e útil para a comunidade na qual está inserida. Em contrapartida, o bibliotecário deve ter consciência de seu papel na sociedade e ter plena capacidade em oferecer serviços de qualidade, atividades bem formuladas e fundamentadas, que vão ao encontro das necessidades específicas do público que atende. O bibliotecário deve, ainda, ser dinâmico e ensinar os usuários a ler para "aprender a aprender, aprender para saber e para ter conhecimento da sociedade que os cerca" (FRAGOSO, 2011, p. 15).

De fato, para que a atuação do bibliotecário seja eficaz, boas práticas devem fazer parte do cotidiano desse profissional. Desenvolver atividades que estimulem o aprendizado, que estejam em consonância com o que a criança aprende na escola e ainda tornar o espaço da biblioteca agradável e propício para o desenvolvimento e interação do público infantil com 
idades diferentes faz com que a biblioteca seja um ambiente indispensável para o desenvolvimento de seus usuários.

Por certo, o desenvolvimento de atividades específicas para a necessidade do públicoalvo da biblioteca contribui para a transformação do estereótipo do bibliotecário, que passa de simples "organizador de livros" para agente promotor de ações culturais e que fomenta a busca pelo conhecimento, guiando os usuários através de um universo abundante em informações.

Dessa forma, o profissional deve estar sempre atualizado em relação às questões de sua área de atuação, procurando fazer da biblioteca um ambiente que seja agradável e instigador para a busca pelo conhecimento.

No que diz respeito ao acervo, Caldin (2001, p. 112) expressa sua preocupação com o bibliotecário que "preocupado com o caráter informativo e didático do material da biblioteca relega, ao segundo plano, algumas vezes, o material de caráter lúdico, indispensável para apurar a sensibilidade estética desse usuário - pequeno em tamanho e grande em exigências".

Devido à grande produção no setor de literatura infantil, o bibliotecário pode ter dificuldades para selecionar o material que irá compor o acervo. Para driblar essa dificuldade, o profissional deve, antes de tudo, ser leitor. Como explica Caldin (2005, p. 165) "o bibliotecário é o profissional que tem contato com os leitores, conhece seus gostos, interesses e necessidades. Está perfeitamente gabaritado para atuar como crítico na seleção do acervo. Se o bibliotecário se comportar como um leitor ávido, não ficará temeroso em listar obras que a biblioteca deverá adquirir".

Conforme ressalta Caldin (2005), alguns dos principais aliados do bibliotecário para a composição do acervo são os concursos literários, feiras nacionais e internacionais e catálogos de autores e editoras, pois constantemente destacam as principais obras da literatura, assim como lançamentos, críticas e resenhas. O profissional que está atualizado sobre o que há de novo na literatura infantil pode perfeitamente montar um acervo que contenha tanto os clássicos quanto obras que são novidades e tratam sobre valores morais atuais e situações cotidianas, deixando o acervo da biblioteca em equilíbrio.

Após a composição do acervo é preciso pensar no tipo de classificação que se aplicará. É evidente que a classificação utilizando tabelas como a Classificação Decimal de Dewey (CDD) não bastam, e de acordo com Pinheiro e Sachetti (2004) as bibliotecas infantis 
necessitam de um método diferenciado, que permita às crianças entenderem o que é indicado para cada idade, que seja acessível e divertido, chamando a atenção para o acervo.

Há muitas maneiras de se classificar as obras: figuras e cores são as mais indicadas por fazerem parte do universo da criança e permitirem rápida assimilação. Na classificação por figuras pode-se utilizar, por exemplo, personagens do folclore brasileiro, contos de fada, etc.

Na visão de Pinheiro e Sachetti (2004, p, 4),

a biblioteca infantil é um ambiente que possui características próprias e sua comunicação visual merece atenção especial: a busca de um sistema de sinalização que utilize recurso de linguagem visual visa não só a estética, mas principalmente a facilidade de uso de seu ambiente, o que proporciona uma melhor interação entre o usuário e a informação.

A classificação em cores deve ser simples e organizada para que se obtenham os efeitos esperados, deve-se também divulgar detalhadamente o método utilizado aos usuários para que eles possam buscar - sozinhos - a informação desejada.

Quanto às ações desenvolvidas nesses ambientes: elas devem despertar a curiosidade das crianças em relação ao espaço e acervo da biblioteca, devem instigar seus usuários a buscarem a leitura para o prazer e aprendizado. Os bibliotecários podem desenvolver projetos que mostrem ao público-alvo tudo o que a biblioteca oferece. Para divulgar o material do acervo, por exemplo, podem-se organizar rodas de leitura, painel de sugestões, hora do conto, teatro de fantoches e outras ações que tenham o mesmo caráter instigador das já citadas.

\section{Considerações metodológicas}

O desenvolvimento deste trabalho possui duas vertentes metodológicas: a primeira relacionada ao levantamento de dados das ações desenvolvidas em bibliotecas infantis nacionais e internacionais e a segunda relacionada com as entrevistas realizadas com bibliotecários que atuam em bibliotecas infantis.

O levantamento de doados das ações foi realizado em duas etapas: 1) Pesquisa sobre bibliotecas infantis brasileiras e estrangeiras, objetivando relacionar e comparar as ações desenvolvidas em cada uma delas, com intuito de fazer um retrato parcial da situação das bibliotecas infantis no país em relação às ações desenvolvidas em bibliotecas infantis estrangeiras. 2) Entrevista com alguns bibliotecários para compor um rol de habilidades e atitudes importantes para o profissional atuante em biblioteca infantil. 
Para o levantamento de dados das ações foi realizada uma busca na internet por meio de um buscador (Google). Nessa busca, os seguintes termos foram utilizados: biblioteca infantil; biblioteca municipal; biblioteca escolar; biblioteca pública; biblioteca para crianças; children's liberar e; public library. Justifica-se a utilização dos termos biblioteca escolar, biblioteca pública e biblioteca municipal, tendo em vista que no Brasil o atendimento ao público infantil dá-se também nessas instituições.

Foram definidos alguns critérios para a seleção das bibliotecas infantis, são eles: a) possuir espaço separado dedicado exclusivamente às crianças (considerando a faixa etária de 0 a 12 anos); b) desenvolver atividades periódicas voltadas ao público infantil; c) possuir um ambiente que ofereça autonomia às crianças, ou seja, possibilite que elas se desloquem livremente pelo acervo e sejam capazes de encontrar o que desejam; d) desenvolver projetos em parceria com a sociedade em que está inserida (comunidade, escola, etc.).

Após realizar a seleção dos sites sobre as bibliotecas infantis foi elaborado um protocolo em planilha do Excel, contendo os dados referentes a cada instituição: 1) descrição das bibliotecas: contendo nome da biblioteca e sua localização 2) descrição das ações desenvolvidas. Foram relacionadas somente as ações informadas no calendário de evento das bibliotecas, disponíveis nos sites.

Quanto à entrevista, foi realizada com cinco bibliotecários. O recrutamento para a participação na pesquisa foi feito por meio da internet. Foi postado um texto em um grupo do Facebook denominado "Biblioteconomia Brasil" procurando profissionais que atuam e/ou atuaram em bibliotecas infantis, dispostos a responderem algumas questões relacionadas à sua atuação. As perguntas foram enviadas por e-mail e Facebook. Uma das entrevistas foi realizada pessoalmente em visita à biblioteca onde a profissional atua. Os nomes das bibliotecas onde os profissionais atuam/atuaram foram preservados.

Após a realização das entrevistas e categorização das ações desenvolvidas nas bibliotecas, as habilidades e atitudes citadas pelos bibliotecários foram comparadas com a literatura e apresentadas em forma de um quadro. ${ }^{1}$

\footnotetext{
${ }^{1}$ Ressalta-se que as competências técnicas não foram citadas neste trabalho, já que se entende que são comuns a todos os bibliotecários, independentemente do ambiente em que atuam
} 


\section{Ações Desenvolvidas em Bibliotecas Infantis}

Após coleta e análise dos dados referentes às bibliotecas infantis, foi realizada a categorização das ações desenvolvidas nesses ambientes. As ações semelhantes foram agrupadas em 16 categorias (Quadro 1) que definem o tipo de atividade realizada em cada instituição.

\section{Quadro 1 - Categorização das ações desenvolvidas em bibliotecas infantis}

\begin{tabular}{l|l|}
$\begin{array}{l}\text { 1.Troca de livros; } \\
\text { 2.Acampamento na biblioteca; }\end{array}$ & $\begin{array}{l}\text { 9.Teatro e cinema; } \\
\text { 10.Festivais, concursos e exposições; } \\
\text { 3.Livros eletrônicos; }\end{array}$ \\
$\begin{array}{l}\text { 11.Atividades para bebês e pré-escolares; } \\
\text { 12.Leitura para cães; } \\
\text { 5.Hora do conto e rodas de leitura; }\end{array}$ & $\begin{array}{l}\text { 13.Central de ajuda; } \\
\text { 14.Alfabetização informacional; } \\
\text { 6.Oficinas e cursos; } \\
\text { 7.Publicidade; } \\
\text { 15.Atividades de estimulo ao contato com a cultura } \\
\text { local e de outros lugares; } \\
\text { 16.Outros. }\end{array}$ \\
\hline
\end{tabular}

Para a composição do Quadro1 foram analisadas 19 bibliotecas infantis que apresentavam sites na internet. Deste total, oito são brasileiras e onze são estrangeiras. As bibliotecas brasileiras são formadas por um grupo com sete bibliotecas públicas e uma biblioteca escolar. As bibliotecas estrangeiras constituem um grupo com 11 bibliotecas que foram escolhidas a partir do ranking realizado pelo site Livability $^{2}$ contendo as 10 melhores bibliotecas para crianças dos Estados Unidos.

Na Figura 1 é possível identificar os resultados obtidos com a categorização das ações desenvolvidas nas bibliotecas brasileiras.

\footnotetext{
2 Livability: America's best places to live and visit - Top 10 libraries for children. Disponível em: <http://livability.com/top-10/top-10-libraries-children/cincinnati/oh>. Acesso em: 05 out. 2012.
} 


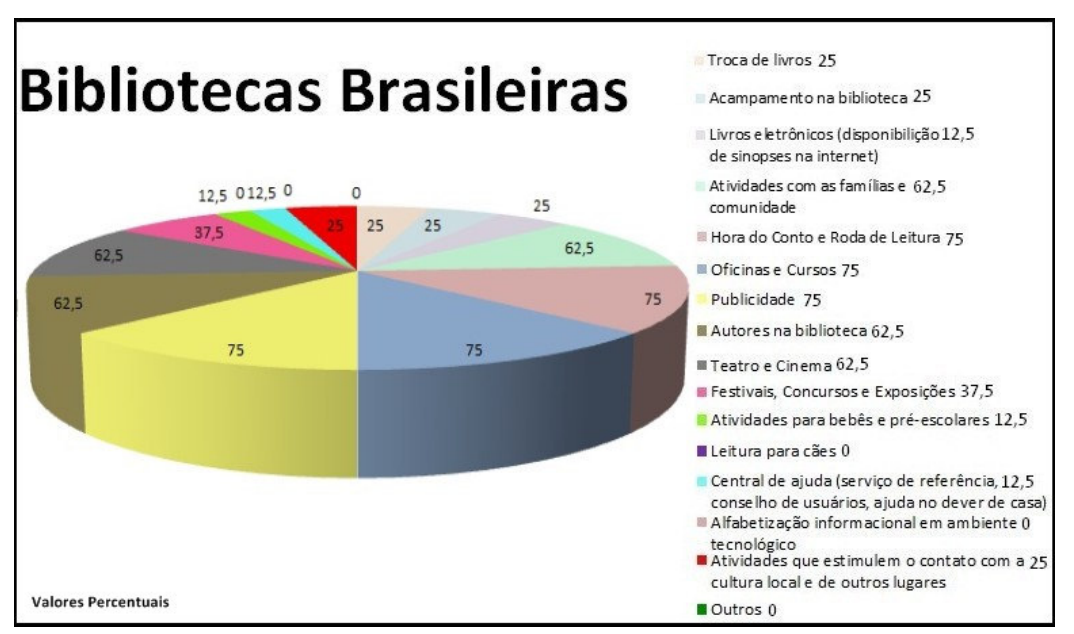

Figura 1 - Ações realizadas nas bibliotecas brasileiras Fonte: Elaborado pelas autoras

Observa-se na Figura 1 que a maioria das bibliotecas brasileiras pesquisadas, além de oferecer uma variedade de serviços aos seus usuários, disponibiliza atividades para a comunidade em que está inserida. Possuem, ainda, atrações para conquistar novos usuários e manter o interesse de quem já utiliza o espaço.

Ações que tornam a biblioteca mais íntima dos usuários são executadas na maioria das bibliotecas brasileiras, tais como hora do conto, oficinas e cursos, teatro e cinema, etc. Não se pode esquecer, ainda, dos festivais e de convidados especiais trazidos pela maior parte dessas bibliotecas.

Apesar de realizarem muitas atividades que buscam o contato mais próximo com o leitor ou futuro leitor, a maioria das bibliotecas brasileiras analisadas foca o desenvolvimento de atividades tradicionais e ações culturais, não priorizando ações de suporte à escola, à alfabetização precoce e a formação de leitores.

É possível que essa prática seja originada da preocupação em levar a biblioteca à comunidade e fazer com que os usuários adquiram hábitos de leitura, tentando mudar o tabu existente ainda hoje no Brasil em relação à instituição, fazendo da biblioteca algo extraordinário, ao alcance somente dos intelectuais.

As bibliotecas estrangeiras, no entanto, demonstram muita criatividade na elaboração de seus projetos para conquistar leitores. Na Figura 2 é notável a variedade de atividades relacionadas com este objetivo: 


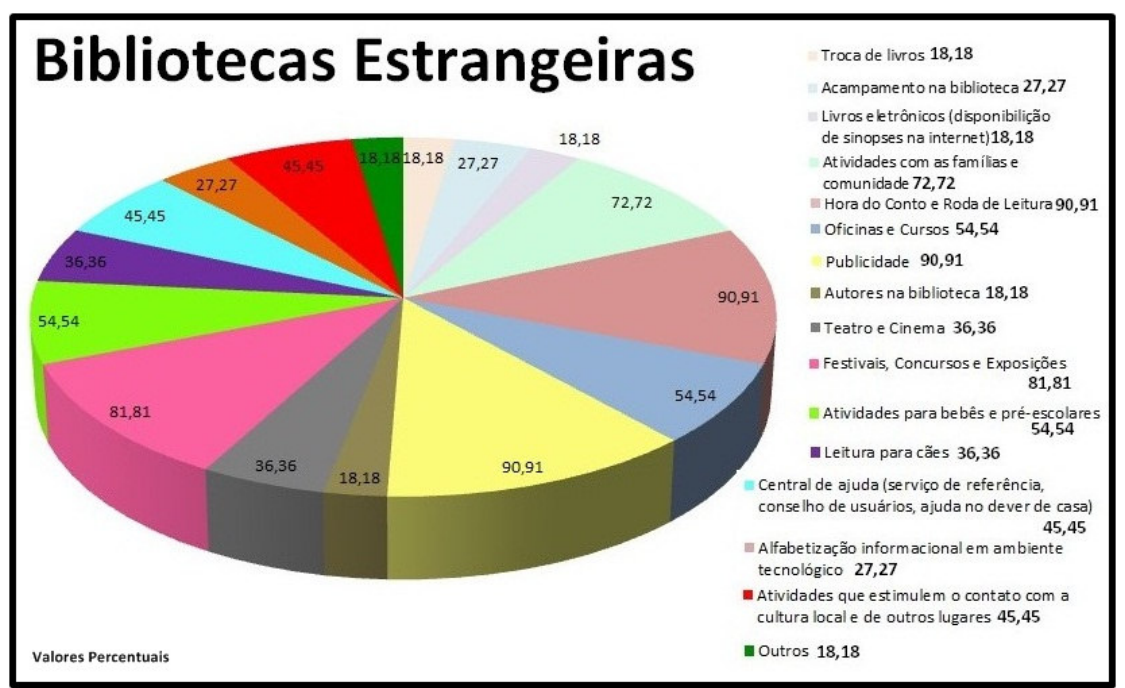

Figura 2 - Ações realizadas nas bibliotecas estrangeiras Fonte: Elaborado pelas autoras

As bibliotecas estrangeiras apresentam uma porcentagem menor de ações como troca de livros, autores na biblioteca, teatro e cinema. O foco das ações está mais voltado a outras formas de conquistar leitores, tais como: festivais, concursos, exposições, ajuda no dever de casa. A relação das ações desenvolvidas nestas instituições privilegia a formação educacional das crianças.

A comparação entre as Figuras 1 e 2 não oferece resultados definitivos, devido ao pequeno número de bibliotecas analisadas e à pesquisa restringir-se apenas aos sites das instituições, no entanto, é necessário reconhecer as diferenças encontradas entre as bibliotecas brasileiras e as estrangeiras. A principal diferença recai na natureza das bibliotecas infantis estrangeiras que são planejadas - e não adaptadas - para o atendimento infantil.

A variedade dos tipos de ações executadas nas bibliotecas infantis é de extrema importância quando se pensa que as crianças estão iniciando o caminho da leitura, principalmente para que a biblioteca não faça justiça ao estereótipo de um lugar exclusivamente dedicado à leitura silenciosa e introspectiva. A biblioteca - e não só a infantil - deve abrigar todos os tipos de leitores, inclusive àqueles que não gostam de ler documentos em suporte de papel.

Tendo em vista os diferenciados perfis de leitores e as diferentes maneiras de uma criança aprender, é necessário que as bibliotecas infantis disponham de um leque bastante amplo de atividades que estimulem a busca pelo conhecimento, seja por meio de contação de histórias, peças teatrais, jogos ou o contato direto com os autores de suas obras preferidas. 
As ações levantadas e analisadas permitem visualizar o quanto é importante a aproximação entre bibliotecários e educadores, buscando alcançar um objetivo em comum: a formação de leitores críticos e conscientes de seu lugar no mundo. Para o desenvolvimento das ações identificadas tanto nas bibliotecas nacionais como nas estrangeiras é preciso que o profissional - bibliotecário - seja criativo e que saiba planejar as ações tendo como meta participar ativamente do processo de formação de leitores.

Independentemente de a biblioteca estar localizada em uma escola ou ter um prédio próprio - no caso de bibliotecas públicas - é imprescindível que o bibliotecário esteja preparado para o desenvolvimento de ações sociais, culturais e também educativas.

\section{Competências dos Bibliotecários que atuam em Bibliotecas Infantis}

A disposição das atividades realizadas em bibliotecas infantis traz à tona a pergunta que permeia este trabalho: qual deve ser o perfil do bibliotecário atuante em bibliotecas infantis para dar conta de realizar ações criativas e eficazes que contribuam efetivamente para a formação de leitores? O profissional deve estar preparado para lidar com um público diferenciado, deve manter o foco de seu trabalho nos pequenos usuários e não somente no preparo técnico do acervo.

Como demonstrado, as bibliotecas infantis necessitam disponibilizar atividades que chamem a atenção das crianças num primeiro momento para, em seguida, conquistá-las com ações ligadas ao mundo da leitura. Estas ações devem se apresentar de forma a não somente distrair a criança, mas ensiná-la a buscar informações da maneira correta e em fontes confiáveis.

Entretanto, para que ações desse tipo sejam realizadas e tragam resultados é de extrema importância que haja um profissional qualificado para desenvolvê-las. Ferrarezi e Castro Filho (2011, p. 116), apresentam algumas qualidades principais para o bibliotecário escolar, tais como a necessidade de que ele seja flexível, comunicativo e saiba lidar com os recursos tecnológicos. Os autores também reforçam a necessidade desse profissional ser dinâmico e, principalmente, ser leitor. Ainda acrescenta-se a paciência e afetividade a esse rol de qualidades, conforme pontua Araújo e Sales (2011). Essas características aplicam-se também ao bibliotecário que atua com o público infantil. 
Em pesquisa realizada com bibliotecários da Rede Municipal de Ensino de Florianópolis, Araújo e Sales (2011, p. 572) levantaram alguns atributos indispensáveis citados pelos bibliotecários formadores de leitores:

\begin{abstract}
ser comunicativo, estar sempre bem informado, ser articulado, dinâmico, conhecer as preferências dos alunos e seu universo. Também foram lembradas características como a perseverança, ser convincente, conhecer os livros de literatura, gostar do que faz, gostar de criança e ter poder de alteridade. Com relação a esta última habilidade, entende-se como fator fundamental ter a capacidade de se colocar no lugar do outro, pois é dessa forma que saberemos como tratar o próximo, a forma de falar com uma criança de cinco anos, por exemplo.
\end{abstract}

A IFLA - International Federation of Library Associations and Instituitions apresenta algumas diretrizes para serviços de bibliotecas para crianças, entre elas instruções para serviços, acervo, publicidade e espaço, estabelecendo também algumas competências necessárias aos profissionais atuantes nesses ambientes.

De acordo com as premissas da IFLA (2003, p. 5), o funcionamento das bibliotecas infantis depende de bibliotecários "especializados no trabalho com essa faixa etária, empenhados e com formação adequada". As competências e habilidades necessárias para a atuação em bibliotecas infantis incluem: entusiasmo; competências fortes de comunicação e relações interpessoais, de trabalho em equipe e de resolução de problemas; habilidades para trabalhar em rede e cooperar; habilidades para iniciar ações, ser flexível e aberto à mudança; habilidade para analisar as necessidades dos utilizadores, planejar, gerir e avaliar serviços e programas; desejo intenso de aprender novas competências e desenvolver-se profissionalmente.

Ainda segundo a IFLA, além das competências citadas é de bom tom que o profissional procure sempre aprofundar seus conhecimentos na área em que atua, buscando maior compreensão do universo infantil em áreas como: psicologia e desenvolvimento infantil; teorias de desenvolvimento e promoção da leitura; oportunidades artísticas e culturais; literatura para crianças incluindo livros e outras mídias.

A seguir apresentam-se as questões e a análise das falas dos profissionais entrevistados buscando-se assim, levantar qualidades consideradas adequadas para atuação do bibliotecário em bibliotecas infantis. Os bibliotecários foram identificados através dos códigos B1; B2; B3; B4; B5, visto que seus nomes foram preservados. 


\section{Quais atividades direcionadas ao público infantil são realizadas na biblioteca onde você atua/atuou?}

Através das atividades realizadas é possível definir as habilidades necessárias ao profissional que as realiza. As respostas correspondem ao ilustrado nas estatísticas sobre atividades. Atividades como Hora do Conto, Teatro, Feira de Livros, Exposições, Apresentações artísticas, entre outras, são práticas comuns nas bibliotecas onde os entrevistados atuam ou atuaram. A adoção de tais práticas nas bibliotecas requer flexibilidade e criatividade por parte dos bibliotecários, tanto para interpretar personagens e contar histórias, quanto para organizar as atividades para que não haja tumultos e todas as crianças possam aproveitar o que lhes foi proposto.

\section{Na biblioteca em que você atua/atuou, de que maneira ocorre o contato inicial das crianças com a leitura?}

Nesta questão, os bibliotecários pontuaram atividades como Contação de Histórias, Prêmio aos Leitores e Empréstimos de Multimídias como forma de incentivar o contato com a biblioteca e a leitura. Entre as atividades citadas, destacam-se duas:

B4 - Biblioteca Ambulante: Percebemos que os alunos maiores não iam à biblioteca com a mesma frequência dos menores, por isso, foi criado este projeto. Uma vez por semana, na hora do intervalo, a equipe da biblioteca sai com o carrinho de madeira recheado de livros. Os alunos podem fazer empréstimo e devolução de livros.

B2 - Projeto contador de histórias, cujo principal objetivo é o incentivo à leitura como atividade agradável e prazerosa, já que ela não pode ser vista apenas como algo obrigatório, mas sim como fonte inesgotável de prazer e conhecimento. Nesse projeto, que envolve turmas dos $3^{\circ} s, 4^{o} s$ e $5^{\circ} s$ anos, cada aluno toma emprestado um livro do acervo para fazer a leitura em casa. Depois, contam a história desse livro para toda a classe (na aula de biblioteca) sem citar, porém, o final, deixando os colegas curiosos e despertando-lhes, assim, o interesse para a leitura. Quando o aluno devolve o livro, já é longa a lista de reserva da obra. Com o tempo, o projeto passou a abrigar textos de outras fontes, como jornais e revistas, ampliando dessa forma a variedade dos gêneros, que agora contemplam os formatos literário e informativo. Por sua participação na exposição oral da história, ou em qualquer atividade de leitura com textos informativos, todo aluno ganha 
uma flor de papel em que estão escritos seu nome, ano e classe, e que depois é colada em uma árvore (feita de madeira). No final do ano, a Biblioteca entrega aos alunos um certificado de Honra ao Mérito pela participação no Projeto Contador de Histórias, com as assinaturas do diretor, da coordenadora pedagógica e da bibliotecária.

O contato inicial com a leitura na biblioteca é fator determinante para os próximos passos das crianças no universo da leitura, o bibliotecário precisa estar preparado para lidar com as particularidades de cada usuário. Para tanto, é preciso que o profissional da informação seja também leitor e conheça, assim, as particularidades tanto da literatura infantil quanto do público que atende, para que possa guiar e tornar prazerosa a trajetória das crianças no universo da leitura.

A biblioteca ainda possui um estereótipo muito forte de ser um lugar silencioso e um local de punição para os que não respeitam as regras. Quando os usuários são crianças, naturalmente agitadas, a prática do silêncio pode não ser a mais adequada. Como deve ser o ambiente da biblioteca nesse sentido?

Como demonstrado no início do trabalho, é necessário adotar novas práticas em bibliotecas cujo público é, em grande parte, infantil. Cabe ao profissional da informação elaborar e manter tais práticas. Um dos bibliotecários, ao ser indagado sobre esse estereótipo, afirmou:

B1 - É na base do brincando, do brincar, do lúdico, que você atrai a criança pra leitura e não a coisa da obrigação como é na escola. Não estou criticando a escola, a escola tem o papel dela, a biblioteca tem o papel dela. Eles não, a gente sabe disso, tem um período da nossa vida que a gente não quer mais ler porque foi tudo obrigação, você tem que ler pra fazer uma prova, você tem que ler pra fazer um trabalho, pra mostrar pra professora. "Você tem que", e esse "você tem que"... é de lascar de ruim, vamos falar a verdade, vira obrigação e a partir do momento que vira obrigação você tem que ter muito tato pra lidar com isso e fazer com que aquilo se dilua e desça de uma forma melhor.

Através dessa resposta, nota-se a importância de se ter disposição e energia, afinal, participar de brincadeiras ajuda a inserir o bibliotecário no universo infantil, fazendo com que 
este profissional entenda melhor seu público e, assim, possa oferecer atividades mais direcionadas as reais necessidades dos pequenos usuários.

Houve consenso entre os bibliotecários sobre a necessidade de tornar a biblioteca um organismo vivo, principalmente por se tratar de um público específico.

Indivíduos que não frequentam a biblioteca e não gostam de ler podem transmitir isso aos filhos. A biblioteca atende crianças que afirmam não gostar de ler? O que o bibliotecário deve fazer para inserir esses usuários no mundo da leitura?

A ausência de bibliotecas nas escolas e a falta de incentivo à leitura desde as séries iniciais fazem com que muitas pessoas não tenham contato com livros ou considere-os 'chatos', ideia que pode ser transmitida de pais para filhos. A biblioteca deve possuir programas de incentivo à leitura, mas também oferecer alternativas para as crianças que não se identificam tanto com livros, pois a leitura não se restringe apenas a esse suporte. Além disso, ao adquirir o hábito de frequentar à biblioteca, a criança vai se familiarizando aos poucos com os livros e tudo que o local oferece. Nesta questão, a obrigatoriedade de frequentar a biblioteca surge novamente, porém com um enfoque diferente por parte de uma bibliotecária escolar:

B2 - Aqui no Colégio, as crianças são obrigadas a frequentar a Biblioteca uma vez por semana, juntamente com a professora, existe um horário já fixado na grade curricular. Como as crianças são incentivadas desde o início da vida escolar, não encontramos esse tipo de problema. Quando a criança diz que não gosta de ler, apresentamos a ela muitas sugestões, até que ela encontre algo que a satisfaça. (Grifo nosso)

Apesar da obrigatoriedade imposta pela escola, há uma tentativa de conquistar as crianças por meio de literatura atrativa, respeitando, porém, -a livre escolha da criança quanto ao que lê (CAVALCANTI, 1982). Comparando o discurso das bibliotecárias que atuam uma em biblioteca escolar e outra em biblioteca pública, é possível observar que o discurso pode variar conforme o ambiente em que a biblioteca está inserida, já que na escola a biblioteca deve estar em harmonia com as atividades pedagógicas, diferente da biblioteca pública, que está livre dessa obrigatoriedade. 


\section{Sabendo que a função do bibliotecário vai além do tratamento técnico documental, qual é o perfil ideal do bibliotecário que lida diretamente com público infantil?}

Para falar sobre o perfil do bibliotecário, os entrevistados citaram algumas habilidades e atitudes ideais para atuação em bibliotecas infantis. Foram selecionados alguns trechos considerados importantes.

B1 - Pelo menos dentro da minha experiência de 22 anos de serviço público e bibliotecas infanto-juvenis, logo de início se você não gostar de criança como é que você vai trabalhar em uma biblioteca infantil/juvenil? E o pior é que você encontra gente que não gosta de criança e que trabalha em biblioteca infantil/juvenil. Mas na nossa área [Biblioteconomia], além do conhecimento bibliotecário você precisa realmente gostar de criança, saber que biblioteca infantil e juvenil é uma biblioteca diferenciada porque eu acho que não só a biblioteca infantil e juvenil tem que ser um organismo pulsante, um organismo vivo, mas a biblioteca de adulto também. [...] Então quem trabalha, uma bibliotecária pra trabalhar em uma biblioteca infantil/juvenil, ela precisa ser alguém com esse pique, não é? Com essa cabeça pensante que tá acontecendo uma coisa ali, tá acontecendo um estudo de uma pesquisa escolar lá em cima, tá acontecendo uma contação de história lá embaixo, tem uma exposição de bonecos e que a criança fica ensandecida, tem uma escola chegando e criança chorando, e você tem que lidar com tudo isso. Agora, claro, tem uma ala da biblioteca que não trabalha com isso, que fica nas salas, fazendo todo um trabalho técnico, preparando vamos dizer toda a parte técnica mesmo bem da biblioteconomia, e aí não se envolvem com todo esse lado. Mas eu acho que se você não quer ficar só na parte técnica, fechada numa sala preparando tecnicamente livros, imprimindo etiquetas e coisa e tal, você tem que ser alguém com um pique muito bom ou, como diz a moçada aí de hoje, você tem que estar numa 'vibe' fantástica, não é? Porque senão você vai dançar, não dá conta e a criança, o jovem vai perceber que você é alguém que não tá no ritmo que eles gostariam que você estivesse.

B2 - [...] As principais características necessárias ao profissional bibliotecário são: liderança, trabalho em equipe, amor à profissão, respeito com as crianças para poder ser respeitado.

B3 - A primeira característica é ser alguém aberto ao novo e que goste de mudanças constantes, pois a biblioteca e as próprias crianças precisam Bibl. Esc. em R., Ribeirão Preto, v. 3, n. 1, p. 51-72, 2014. 
disso, precisa ser uma pessoa dinâmica e com muita criatividade para poder proporcionar as crianças um ambiente de leitura prazeroso.

B4 - O bibliotecário de uma biblioteca infantil, além de gostar de crianças, deve buscar despertar o interesse das crianças pela leitura. Na verdade o bibliotecário escolar deve ser dinâmico, criativo e desinibido. Às vezes é preciso que o bibliotecário use a imaginação para mostrar às crianças como é prazeroso ler. Para tanto, pode ser necessário que se fantasie, decore a biblioteca, faça atividades de pintura, canto, dança. O profissional, além de paciente, também deve ter jogo de cintura para lidar com as perguntas capciosas feitas pelas crianças.

B5 - Algumas competências se tornam essenciais para atuação nas bibliotecas infantis: possuir um aparato informacional do universo letrado;

Ter habilidade para trabalhar com ação cultural;conhecer realmente o que significa inovar;ter empatia com o público infantil, entre outras competências. (Grifo Nosso)

No discurso dos bibliotecários entrevistados é notável a consciência de que o bibliotecário de bibliotecas infantis é um profissional diferenciado e as competências citadas por eles vão ao encontro do que é dito na literatura, buscando sempre atender da melhor maneira as particularidades do público infantil. Nota-se ainda na resposta fornecida por B5, a consciência de que o bibliotecário precisa saber lidar com ações culturais, reforçando a ideia de que o foco das bibliotecas brasileiras é a formação cultural.

A biblioteca tem uma importante função na educação das crianças, pois é um local no qual as crianças vão para realizar suas pesquisas escolares e onde os professores procuram suporte para suas aulas. Neste ambiente é o bibliotecário que vai apresentar as fontes de pesquisa, ensinar a maneira correta de buscar a informação e incentivar a leitura. Neste sentido pode haver alguma confusão entre os papéis do professor e do bibliotecário?

É necessária a colaboração entre professor e bibliotecário, principalmente nas bibliotecas escolares. Essa pergunta pretendeu verificar se há confusão entre esses papéis tendo em vista que, como mediador da informação, o bibliotecário também deve fazer parte do ensino. Os bibliotecários entrevistados reconhecem que pode haver confusão por parte das crianças, porém os papéis são distintos: 
B5 - Pode parecer tênue o limite das funções do professor e bibliotecário. No entanto, o ideal é que um seja parceiro do outro, sem que haja confusão nas atuações e sim uma congruência. Há necessidade de uma construção coletiva destes papéis, com objetivos comuns e atuações conjuntas. É importante destacar que cada profissional deve focar sua dimensão em suas ações, sem ignorar o ponto de vista do outro. Exemplificando: os professores fazem frequentemente contação de histórias e os bibliotecários podem ou não fazer, dependendo de sua habilidade, de qualquer maneira é ação exercida pelos dois profissionais em questão. Neste sentido ocorre uma congruência de ações, com distintos focos. O professor pode utilizar a literatura como motivadora para um tema a ser trabalhado. O bibliotecário pode enfocar o entretenimento. E mesmo que haja a mesma finalidade são atores diferentes com formações diferentes o que certamente será percebido na execução da contação de história.

B3 - Pode haver confusão se as partes não se entenderem, pois os papéis são bem específicos e as formações também, cabe ao professor e ao bibliotecário saber onde começa e termina o limite do outro, podendo assim realizar um ótimo trabalho em conjunto para a formação dessas crianças como futuros leitores.

B4 - O cenário da biblioteca infantil é propício para a confusão entre os papéis do professor e o do profissional da educação. Os alunos, principalmente os de menor idade, não conseguem distinguir a diferença entre os papéis. Mas creio que, em um ambiente escolar, o bibliotecário, além de profissional da informação, também assume a atribuição de educador. Por isso, a importância de o perfil de um bibliotecário em uma biblioteca infantil ser diferente do de um profissional da informação que atue em outros tipos de biblioteca. Dependendo da forma com que o bibliotecário desempenhe suas atribuições pode ou não refletir no comportamento da criança como leitora.

Outro bibliotecário usa a própria experiência para exemplificar a diferença entre o papel do professor e do bibliotecário:

B1 - Não. É o que a gente chama, e tem cursos pra isso inclusive, de mediação de leitura. Você é um mediador de leitor, de leitura e do leitor. Você, de uma certa forma, acaba sendo também um educador, não é? O professor não gosta de ser comparado ao bibliotecário e o bibliotecário não

Bibl. Esc. em R., Ribeirão Preto, v. 3, n. 1, p. 51-72, 2014. 
gosta de ser comparado ao professor e eu acho que são sim diferentes, mas no papel que a gente faz aqui, como bibliotecária de uma biblioteca infantil e juvenil, você acaba tendo um bocado o papel de educador, de educadora, porque você tá mediando a leitura, mediando o leitor e ensinando, passando coisas, ensinando coisas pra ele que muitas vezes melhora no desenvolvimento dele na escola. O que eu muitas vezes faço aqui com os meninos que jogam futsal e que depois vêm para o encontro de leitura e literatura comigo, tem meninos que tinham uma dificuldade muito grande pra ler, era um verdadeiro horror. E hoje, faz pouco tempo que estou com eles, desde novembro do ano passado e tem menino que já tá lendo com mais desenvoltura, tá lendo melhor. O que é isso? É um trabalho que tá sendo feito aqui, brincando, na base da brincadeira. Porque eu deixo claro pra eles: eu não sou professora e aqui não é aula: é um encontro que a gente tem depois de vocês terem jogado futebol, pra vocês acalmarem, assentarem, acabar o suor. Vamos nos encontrar aqui, a gente fica lá no auditório, alguma sala de multiuso lá em cima, onde tiver desocupado. Já brincamos até na praça [do parque onde está localizada a biblioteca], de brincar mesmo, não teve leitura! Eu deixei os livros de lado, o sapato, a meia, dobrei a barra do jeans e me sentei na areia e ficamos fazendo castelos de areia! Aí um dos meninos depois viu os livros e falou "Ah! Eu posso pegar um livro pra ler?" "Claro que pode!". E o que ele fez? Enquanto a gente brincava, era um livro de poesia sobre futebol, ele ficou lendo as poesias para nós em voz alta e a gente fazendo brincadeira na areia com castelos de areia, veja você! Isso faz parte também, e isso me aproximou deles e eles de mim, então é muito interessante! E graças a Deus melhorou na leitura de dois meninos pequenos que vem aqui e que a gente vai fazendo esse bate-bola, eles batem a bola lá na quadra do futsal e depois eles batem a bola na leitura e na literatura comigo, não é? E eu acho que eu ajudo, então que papel é esse que eu bibliotecária estou fazendo, ou quem quer que fosse que estivesse no meu lugar, não é? Tá de uma certa forma, mediando a leitura, com absoluta certeza, mas de uma certa forma fazendo um trabalho de educadora, não é? E de cada vez ir abrindo mais a cabecinha dessa molecada pra leitura, pra literatura, pra história, pra ver que é importante ler e saber ler porque o mundo vai se abrindo a sua frente né? Quem lê sabe mais, isso é uma coisa mais certa que dois e dois são quatro.

Bibl. Esc. em R., Ribeirão Preto, v. 3, n. 1, p. 51-72, 2014. 
Apesar do papel do bibliotecário ser passível de confusão com o de professor por parte das crianças, mas há uma diferença, uma vez que o profissional da informação atua como mediador da leitura de maneiras diferenciadas mostrando ao leitor as formas de entretenimento proporcionadas por esse universo, enquanto que o professor ainda fica limitado pelos padrões formais da escola e sua responsabilidade não é restrita à leitura.

\section{Perfil Proposto para a Atuação do Bibliotecário em Bibliotecas Infantis}

Entende-se como competência o aperfeiçoamento de habilidades que em conjunto com conhecimentos e atitudes específicas permitem uma atuação diferenciada. Habilidade pode ser definida então, como a facilidade natural que uma pessoa tem para desenvolver certas atividades, algo intrínseco. Competência é a capacidade de desenvolver atividades devido ao aperfeiçoamento profissional, algo adquirido com estudos ao longo do tempo.

Reunindo todas as características expostas nesse trabalho - tanto na literatura quanto nas entrevistas - tem-se um profissional com as principais qualidades necessárias para lidar com o público infantil, conforme Quadro 2.

Quadro 2 - Habilidades e atitudes propostas para atuação do bibliotecário em biblioteca infantil

1. Afetividade;

2. Comunicabilidade;

3. Conhecer bem o público;

4. Criatividade;

5. Dinamicidade;

6. Flexibilidade;

7. Ser leitor;

8. Ter ânimo e disposição

9. Paciência;

10. Ser proativo;
11. Saber avaliar serviços e programas;

12. Saber lidar com tecnologias de informação e comunicação;

13. Saber trabalhar em equipe;

14. Ser bem informado;

15. Ter poder de alteridade;

16. Ser inovador;

17. Ter amor pela profissão;

18. Gostar de crianças;

19. Ser desinibido;

20. Propor e executar projetos.

Justapondo as competências citadas ao longo do trabalho, observa-se que além das características necessárias a todos os bibliotecários, os que atuam em bibliotecas infantis devem apresentar habilidades e atitudes específicas para o atendimento do público infantil, além de buscar constantemente o aperfeiçoamento profissional não só na área de Biblioteconomia e Ciência da Informação, mas também nas áreas que tratam do desenvolvimento infantil. A congruência dessas qualidades contribuem para a aproximação do 
público infantil e, por sua vez, contribui da formulação de atividades que corroborem para a formação de leitores críticos.

\section{Considerações finais}

A biblioteca sofreu grandes mudanças ao longo do tempo, fala-se muito sobre a importância da leitura, mas pouco é feito para incentivar tais práticas. O papel da biblioteca é formar leitores críticos, que entendam o que acontece na sociedade e possam diferenciar e usufruir da informação que gera conhecimento.

Apesar de ser importante, a biblioteca às vezes é considerada depósito de livros, local onde é necessário fazer silêncio e sempre devolver o material no prazo estipulado. Em uma paródia da música "Cálice" de Chico Buarque, o cantor Criolo expõe a imagem que a biblioteca tem na sociedade:

\section{(...) os saraus tiveram que invadir os botecos \\ Pois biblioteca não era lugar de poesia Biblioteca tinha que ter silêncio, \\ E uma gente que se acha assim muito sabida.}

O bibliotecário é o agente transformador desse estereótipo, e deve buscar sempre novas maneiras de levar à sociedade todas as possibilidades que o universo da leitura oferece.

As entrevistas com os profissionais da informação que atuam ou atuaram em bibliotecas infantis, bem como a literatura, reforçam a necessidade de renovação desse ambiente a fim de cumprir o seu papel na formação de leitores. Para que se forme um leitor é necessário incentivar o hábito da leitura e, como disse Caldin (2001), o público pode ser pequeno em tamanho, mas grande em exigências.

Cabe ao profissional da informação observar as necessidades de seu público, informarse com os profissionais da área, espelhar-se em exemplos de sucesso e investir todo seu esforço e conhecimento para tornar a biblioteca infantil um lugar comum para as crianças, onde possam aprender a ler, aprender com o que lêem, e que possam se divertir com a própria leitura, com ações como hora do conto, teatro de fantoches, entre outros.

Por fim, sugere-se a biblioteca infantil como um local lúdico de incentivo a leitura, local no qual o bibliotecário e educadores podem aliar forças para alcançarem um objetivo 
comum: formar um leitor apaixonado, que saiba interpretar o que se lê e desenvolver a criatividade ao viajar por um mundo de imaginação.

\section{Referências}

ARAÚJO, P. C.; SALES, F. O bibliotecário e a formação de leitores. Revista ACB:

Biblioteconomia em Santa Catarina, Florianópolis, v. 16, n. 2, p. 562-578, jul./dez., 2011.

BUENO, S. B.; STEINDEL, G. E. A biblioteca e a brinquedoteca: mediadores do livro, objeto prazeroso de saber e lazer no ambiente escolar. Ciências e Cognição, Rio de Janeiro, v. 8, p. 1021, 2006.

CALDIN, C. F. O bibliotecário, a criança e a literatura infantil: algumas ponderações. ACB: Biblioteconomia em Santa Catarina, Santa Catarina, v. 6, n. 1, p.111-128, 2001.

Reflexões acerca do papel do bibliotecário de biblioteca escolar. ACB:

Biblioteconomia em Santa Catarina, Santa Catarina, v. 10, n. 2, p. 163-168, 2005.

CAVALCANTI, A. M. F. A. Criança, primeiro leitor. Caderno de Biblioteconomia, Recife, v. 5, p. 22-27, jun. 1982.

FERRAREZI, L.; CASTRO FILHO, C. M. Atuação profissional na biblioteca escolar: outras perspectivas. In: CASTRO FILHO, C. M. ; ROMÃ̃, L. M. S. (Org.). Dizeres sobre biblioteca escolar: palavras em movimento. Ribeirão Preto: Alphabeto, 2011, p. 109-120.

FRAGOSO, G. M. A lei e seus desdobramentos. Salto para o futuro, ano 21, boletim 14, p.12-17, 2011.

INTERNATIONAL FEDERATION OF LIBRARY ASSOCIATIONS AND INSTITUITIONS (IFLA). Directrizes para serviços de bibliotecas para crianças. 2003. Disponível em:<http://archive.ifla.org/VII/s10/pubs/ChildrensGuidelines-pt.pdf >. Acesso em: 10 mar. 20014.

MELO, M. P.; NEVES, D. A. B. A importância da biblioteca infantil. Biblionline, v. 1, n. 2, 2005. Disponível em: <http://periodicos.ufpb.br/ojs/index.php/biblio/article/view/584/422>. Acesso em: 30 ago. 2012.

MOLLO, G.; NÓBREGA, M. J. Biblioteca escolar: que espaço é esse?. Salto para o futuro, ano 21, boletim 14, p.3-11, 2011.

PINHEIRO, M. I. S.; SACHETTI, V. F. P. Classificação em cores: uma alternativa para bibliotecas infantis. In: SEMINÁRIO BIBLIOTECA ESCOLAR: espaço de ação pedagógica, 3., 2004, Belo Horizonte. Anais... Belo Horizonte: UFMG, 2004. Disponível em: <http://gebe.eci.ufmg.br/downloads/319.pdf >. Acesso em: 29 ago. 2012.

SILVA, E. T. A dimensão pedagógica do trabalho do bibliotecário. In: Leitura na escola e na biblioteca. Campinas: Papirus, 2005, p. 67-83. 